\title{
Vida útil de carne fresca de res envasada al vacío a $0^{\circ} \mathrm{C}$ y $+4^{\circ} \mathrm{C}$
}

\author{
García A. L. ${ }^{1}$ - Brugnini. G. ${ }^{2}$ - Rodriguez S. ${ }^{3}$ - Mir A. ${ }^{4}$ \\ Carriquiry J. ${ }^{5}$ - Rufo C. ${ }^{6}$ - Briano B. ${ }^{7}$ \\ Tecnológico de Pando, Facultad de Química \\ Universidad de la República, Uruguay
}

Recepción: 19/07/2015

Aceptación: 26/08/2015

\section{Resumen}

El objetivo de este trabajo fue determinar la vida útil de cortes cárnicos envasados al vacío y almacenados a $0^{\circ} \mathrm{C}$ y $4^{\circ} \mathrm{C}$. Se evaluaron parámetros fisicoquímicos ( $\mathrm{pH}$, porcentaje de Drip, rancidez por Kreiss), aspecto del corte (estado del envase, color del corte, grasa, olor); y aspectos microbiológicos (recuentos en placa de bacterias aerobias mesófilas, enterobacterias, Escherichia coli, coliformes totales, bacterias ácido lácticas) en cortes de bife y picaña durante 5 meses.

En los cortes almacenados a $4^{\circ} \mathrm{C}$ se observaron alteraciones fisicoquímicas y de aspecto en el tercer mes (pH $<5.4$, perdida de vacío y presencia de olores ácidos); mientras que a $0^{\circ} \mathrm{C}$ no se percibieron alteraciones hasta el quinto mes. Por otro lado, no se observó crecimiento significativo para E.coli ni coliformes totales durante el periodo en estudio.

El almacenamiento de cortes envasados al vacío y mantenidos a $0^{\circ} \mathrm{C}$ contribuye a la calidad del producto, y mantiene sus características fisicoquímicas y sensoriales en condiciones comercialmente aceptables durante cuatro meses, permitiendo su transporte hasta destinos distantes.

Palabras clave: envasado al vacío, vida útil, carnes envasadas

\begin{abstract}
The aim of this work was to determine the shelf life of vacuum-packed eat cuts and stored to $0^{\circ} \mathrm{C}$ and $4^{\circ} \mathrm{C}$. There were evaluated physicochemical parameters ( $\mathrm{pH}$, Drip percentage, rancidity by Kreiss), cut appearance (state of container, color of the cut, fat, smell); and microbiological aspects (Plate counts of aerobic mesophilic bacteria, enterobacteriaceace, Escherichia coli, total coliforms, lactic acid bacteria) in cuts of beef and cattle prod during 5 months.

In the cuts stored at $4^{\circ} \mathrm{C}$, there were observed psychochemical and appearance changes during the third month (pH $<5.4$, loss of vacuum and existence of sour odor); whereas at $0^{\circ} \mathrm{C}$, there were not perceived changes until the fifth month. On the other hand, there was not observed any meaningful growth neither to E. coli nor to the total coliforms during the study period.

The storage of vacuum-packed cuts and kept at $0^{\circ} \mathrm{C}$ contributes to the quality of the product, and keeps its psychochemical and sensory features in commercially acceptable conditions during four months, allowing its shipping to away destinations.
\end{abstract}

Key words: vacuum-packed, shelf life, packed meats

1. Licenciado en Ciencias Biológicas, e-mail: gfanalaura@gmail.com

2. Ingeniero Alimentario, e-mail: gbrugnini@fq.edu.uy

3. Secundaria Complementa-Doctoranda en Ciencias Veterinarias opción higiene inspección-control y tecnología de los alimentos de origen animal, e-mail:m.sol.r88@gmail.com

4. Tecnóloga Químico, e-mail: amirhansen@gmail.com

5. Ingeniero Químico, e-mail: carricas@gmail.com

6. P.hD en Nutrición y Biología Molecular, e-mail: caterinarufod@gmail.com

7. Ingeniera Química, e-mail: bbrianocal@gmail.com 


\section{Introducción}

La vida útil de los alimentos entre ellos la carne vacuna fresca, puede definirse como el tiempo máximo en el que se mantienen sus cualidades nutricionales, sensoriales, microbiológicas y de inocuidad en niveles aceptados por los consumidores. La producción actual de alimentos requiere de la aplicación de diversas tecnologías para garantizar la calidad del producto a lo largo de toda la cadena en un contexto de globalización del comercio, en el cual se da una tendencia creciente a preferir aquellos alimentos percibidos como frescos. Por lo tanto, las estrategias para prolongar la vida útil de un producto deben contemplar estos aspectos.

En el caso de la carne, el deterioro es un proceso complejo en el que se dan una combinación de mecanismos químicos y biológicos que vuelven al producto inaceptable (Gram et al., 2002). Aparte de la oxidación de las grasas y las reacciones enzimáticas que puedan ocurrir, el deterioro de la carne puede considerarse mayoritariamente como el resultado de la actividad de una amplia variedad de microorganismos que pueden crecer sobre la superficie de la misma dadas sus condiciones óptimas en nutrientes (Nychas et al., 2007, 2008). La modificación de parámetros como temperatura de almacenamiento y disponibilidad de $\mathrm{O}_{2}$, permiten controlar el crecimiento de los microorganismos que pudieron es- tablecerse sobre la superficie de la carne al finalizar el proceso.

El envasado al vacío mantiene las características sensoriales y organolépticas del alimento por un mayor tiempo (Gill y Harrison, 1989; Rodas-González et al., 2011) como consecuencia del impedimento del crecimiento de microorganismos aerobios degradativos, como Pseudomonas spp y Enterobacteriaceae, normalmente encontrados en carnes (Nychas et al., 2008). La combinación de envasado al vacío con condiciones de almacenamiento a bajas temperaturas (entre $0^{\circ} \mathrm{C} \mathrm{y} 4^{\circ} \mathrm{C}$ ) favorece la selección de especies anaerobias facultativas y psicrótrofas que se desarrollan más lentamente, $y$ tienen menor potencial para generar sustancias que puedan ser rechazadas por los consumidores.

En carnes enfriadas envasadas al vacío con un pH entre 5.3 y 5.8, las bacterias ácido lácticas son las que se desarrollan mayoritariamente; y entre las mismas, las que pertenecen a los géneros Lactobacillus, Leuconostoc y Carnobacterium (Lucquin et al., 2011; Vold et al., 2000; Gill and Greer, 1993; Gill and Gill, 2005), siendo las responsables de la producción de aromas fuertemente lácticos y ácidos cuando su número alcanza las $10^{7} \mathrm{ufc} / \mathrm{g}$. También es posible que se desarrollen en estas condiciones bacterias productoras de gases como algunas especies pertenecientes al género Clostridium y bacterias Gram negativas 
de la familia Enterobacteriaceae, la producción de gases dentro del envase genera la distensión del mismo provocando el rechazo del producto con las consecuentes pérdidas económicas (Brightwell et al., 2007).

En las condiciones de envasado al vacío, la temperatura de almacenamiento es el factor determinante de la velocidad de crecimiento de los microorganismos causantes del deterioro; por lo tanto, las bajas temperaturas prolongarán la vida útil de la carne. La mínima temperatura a la que puede estar la carne envasada al vacío sin congelarse es $-1.5^{\circ} \mathrm{C}$; cuanto más cercana a esta temperatura se almacene la carne, mayor será su vida útil (Gill, 2002, 1988).

Uruguay es un país exportador de carne envasada al vacío, que comercializa sus productos a Europa, Estados Unidos y China, entre otros. Para llegar a estos mercados lejanos con óptima calidad del producto es imprescindible la determinación de la vida útil de los cortes vacunos envasados al vacío. Por lo tanto, el objetivo de este trabajo fue determinar la vida útil comercial de cortes cárnicos envasados al vacío y almacenados a temperaturas de $0^{\circ} \mathrm{C}$ y $4^{\circ} \mathrm{C}$, mediante su evaluación fisicoquímica, sensorial y microbiológica, durante un período de 5 meses.

\section{Materiales y métodos}

\subsection{Muestreo y preparación de las muestras}

Las muestras se tomaron en un frigorífico autorizado para el consumo interno y para la exportación, que opera en condiciones que pueden considerarse representativas de la producción nacional por el volumen de ganado faenado y la tecnología que utilizan. La carne utilizada provino de animales de una misma tropa con características similares en cuanto a su genética, alimentación, estado nutricional y manejo. Se seleccionaron dos de los cortes cárnicos de exportación de más valor, los cuales fueron bife angosto y picaña.

En Uruguay se le llama bife angosto al corte entre la $11^{\mathrm{a}}$ y $13^{\mathrm{a}}$ vértebras dorsales y lumbares, compuesto por los músculos largo dorsal, multífido dorsal, serrato posterior y porciones de músculos intercostales; y picaña a la región de la grupa, compuesta por la porción superior y anterior del músculo bíceps femoral (Figura 1). 

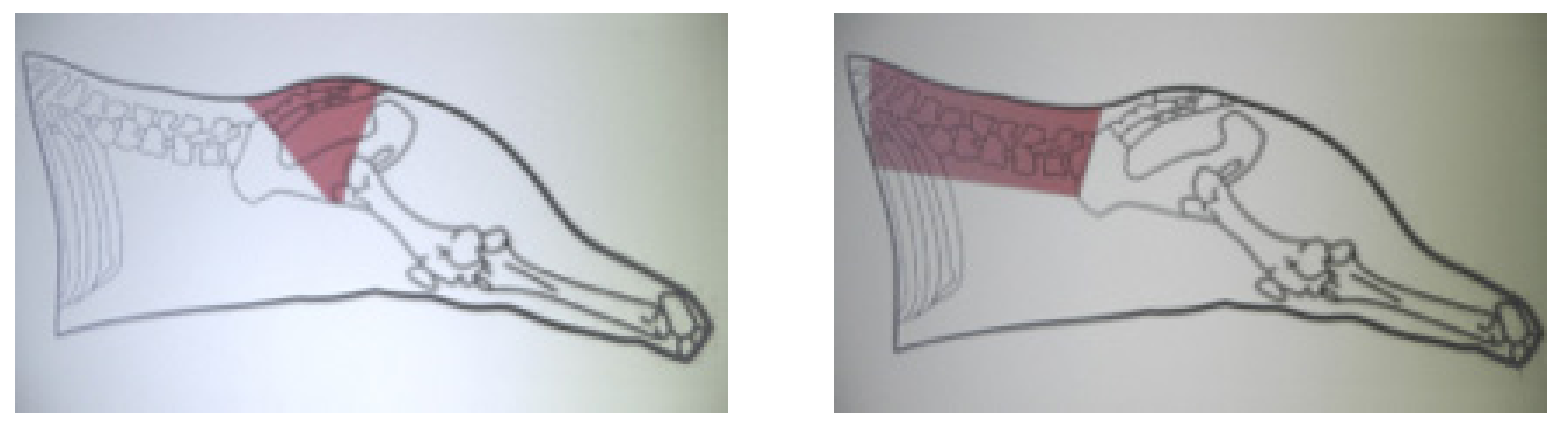

Figura 1. Ubicación de los cortes Picaña (izquierda) y Bife angosto (derecha).

Fuente. Manual de Carnes Bovina y Ovina. Handbook of Uruguayan Meat. Instituto Nacional de Carnes (INAC 2004).

Los mismos se tomaron en la sala de desosado del frigorífico y se envasaron al vacío. Para el envasado al vacío se utilizaron bolsas impermeables al oxígeno marca Maraflex $\mathrm{CH} 046$ HR 388, y una envasadora marca Supervac ${ }^{\circledR}$, modelo GK652 (Viena, Austria). Inmediatamente, luego de su empaque, los cortes fueron separados en dos grupos y almacenados en distintas cámaras, a temperatura de $0^{\circ} \mathrm{C}$ y $4^{\circ} \mathrm{C}$, registrando la fecha de ingreso.

Se analizaron un total de nueve cortes de bife angosto (BA) de aproximadamente 3.5 kilos; y diecisiete muestras de picaña $(P)$ de $1.5 \mathrm{ki}$ los. Las muestras de bife angosto fueron divididas en dos mitades mediante un corte longitudinal. Cada una de ellas fue envasada por separado, obteniéndose un total de dieciocho muestras de BA. Una mitad de cada corte se conservó a $0^{\circ} \mathrm{C}$, mientras que la otra se conservó a $4^{\circ} \mathrm{C}$.
Mensualmente fueron removidas muestras correspondientes a cada corte y a cada temperatura de almacenamiento para su evaluación general. Se consideró el tiempo 0 el momento de la faena.

\subsection{Análisis de las muestras}

\section{Inspección del envase}

El estado general del envase se evaluó de acuerdo al Manual de control de calidad de carnes del Instituto Nacional de Carnes - INAC (INAC 2009) para categorizar las muestras. Este manual clasifica los defectos del empaque en tres niveles: 1) menor, presencia de pequeñas burbujas de aire en el jugo o exudado; 2) mayor, presencia de aire entre el producto y la bolsa, y 3) crítico, en donde hay una falla total del vacío. El nivel 1 se considera aceptable, mientras que los otros niveles descalifican a la muestra. 


\section{Ensayos fisicoquímicos}

\section{a. Medida de $\mathrm{pH}$}

Utilizando un pHmetro Hanna ${ }^{\oplus}$ modelo 9025c se midió y registró el pH del interior de cada corte mediante un electrodo de pincho para carne, el cual se introdujo en la misma aproximadamente $2.5 \mathrm{~cm}$ de forma perpendicular a la superficie del corte. Entre cada muestra, el electrodo fue enjuagado con agua destilada y secado con papel. Se realizaron dos medidas para cada corte y se promediaron: en el caso del bife angosto se midió en el punto más cercano al cuadril, y en el lado del bife ancho; para el caso de la picaña se midió en la base y en el ápice del corte.

\section{b. Rancidez oxidativa}

Se determinó mediante el ensayo de Kreiss (Centro de investigación y tecnología de carnes del sistema INTI, 1932), sobre $25 \mathrm{ml}$ de grasa fundida. Para esto se tomaron al menos $50 \mathrm{~g}$ de la grasa de cobertura de los cortes utilizando un bisturí esterilizado y fue fundida durante cinco minutos en microondas a potencia controlada $(50 \%$ de la potencia máxima). Posteriormente se agregaron $10 \mathrm{ml}$ de ácido clorhídrico concentrado y $10 \mathrm{ml}$ de solución de Floroglucinol al $0.1 \%$ en éter, y se agitó vigorosamente. La formación de color rojo, rosa y/o violáceo indica rancidez de la muestra.

\section{c. Volumen de exudado y porcentaje de drip}

El volumen de exudado se recogió al abrir el envase utilizando probeta de vidrio graduada. A su vez, se pesaron los cortes antes y después del almacenamiento y se calculó la merma expresada como el porcentaje de goteo o drip. De acuerdo a las especificaciones técnicas establecidas en el Manual de Control de Calidad de Carnes (INAC 2009), se considera un defecto menor cuando el porcentaje de drip se encuentra entre 3-5\% y mayor cuando es superior al 5\%, dejando de ser aceptable.

\section{Ensayos sensoriales}

a. Olor

Se realizaron dos observaciones: la primera al abrir el envase, denominada "primer olor", y la segunda a los diez minutos luego de abierto el envase, denominada "segundo olor". Considerando que se trata de carne envasada al vacío, se tomó como normal el olor levemente ácido para el primer olor. Los olores definidos como ácidos y muy ácidos que persisten al abrir el corte se consideraron inadecuados. Luego de diez minutos, el olor ácido debe desaparecer y comenzar a percibirse el olor sui-generis correspondiente a la carne fresca (Spooncer, 1988; INAC 2009).

\section{b. Color del corte}

En este ensayo un panel de cinco consumidores entrenados observó y calificó el color en la 
carne envasada y el color en la carne luego de abierto el envase a los $10 \mathrm{y}$ a los 30 minutos. Se consideraron valores adecuados el color violáceo antes de la apertura y el rojo brillante una vez abierto el envase.

\section{b. Color de la grasa}

Fue determinado por el mismo panel de consumidores de forma visual, y se preestableció un valor estándar normal y aceptable de color crema para la grasa de cobertura. Desviaciones de este color se tomaron como defectos.

\section{Evaluación microbiológica}

Las muestras para microbiología fueron tomadas de forma aséptica inmediatamente luego de la apertura de los envases y trabajadas sobre superficies desinfectadas. Un operador con guantes estériles, escindió un trozo de $20 \mathrm{~cm}^{2}$ (equivalente a $10 \mathrm{~g}$, aproximadamente) de cada muestra con un cuchillo esterilizado. Los instrumentos utilizados para los cortes fueron desinfectados entre muestra y muestra. Estos trozos fueron depositados individualmente en bolsas estériles para Stomacher, y posteriormente homogeneizados con $90 \mathrm{ml}$ de buffer Butterfield.

Para los análisis microbiológicos del exudado, se tomó $1 \mathrm{~mL}$ del exudado total de las muestras de BA y $\mathrm{P}$ con pipetas descartables estériles, y se hicieron diluciones seriadas en tubos de ensayo estériles con $9 \mathrm{~mL}$ de buffer Butterfield. Se sembró $1 \mathrm{~mL}$ de las diluciones correspondientes para las muestras de carne y $1 \mathrm{ml}$ de las diluciones correspondientes para las muestras de exudado. Para el recuento de bacterias mesófilas aerobias, enterobacterias, E.coli y coliformes totales se utilizaron las placas Petrifilm $3 \mathrm{M}^{\oplus}$, correspondientes para cada tipo de microorganismo y se procedió según las especificaciones del fabricante.

Las bacterias acido lácticas se cultivaron en agar MRS (Oxoid ${ }^{\circledR}$ ) y fueron sembradas en placas de Petri estériles entre una doble capa de agar MRS para crear microaerofilia.

Los microorganismos fueron incubados en estufa de cultivo marca Memmert $\mathrm{GmbH}$ modelo BR 300 a sus correspondientes temperaturas y tiempos. Las bacterias aerobias mesófilas se incubaron durante 48 horas a $35^{\circ} \mathrm{C}$. E. coli, coliformes totales y enterobacterias fueron incubadas por 24 horas a $35^{\circ} \mathrm{C}$, y las bacterias ácido lácticas se incubaron durante un período de 72 horas a $25^{\circ} \mathrm{C}$. Transcurrida la incubación se prosiguió al recuento de colonias características de cada tipo de microorganismo estudiado, y se expresaron como log ufc/mL para el exudado y como log ufc/g para la carne.

\section{Ensayo de muestras re-envasadas}

Debido a que en los mercados de destino de la carne uruguaya es habitual que se fraccionen los cortes en porciones unitarias y se reenvasen para su venta minorista, un grupo de 
muestras - luego de abiertas - fueron re-envasadas al vacío y almacenadas en las mismas condiciones, de forma de simular dicho proceso. Se reevaluaron sus parámetros sensoriales a los 15 días de haber sido re envasadas. Se realizaron dos grupos de ensayos diferentes: en uno se partió de muestras tomadas en el segundo mes de almacenamiento; y en el otro se partió de muestras en el cuarto mes de almacenamiento.

\section{Resultados y discusión}

Estado del envase

Para los cortes almacenados a $4^{\circ} \mathrm{C}$, a partir del segundo mes, se comenzó a detectar envases con defectos menores pero aceptables. A los tres meses de envasado los defectos observados se clasificaron como mayores y críticos (pérdida de vacío), estando presentes en el $78 \%$ de los envases; y a los 4 meses, el 100\% de los envases presentaban un estado crítico. Para los cortes conservados a $0^{\circ} \mathrm{C}$ se observó la presencia de defectos menores recién a partir de los 4 meses, y solamente en un $11 \%$ de las muestras, aumentando al $67 \%$ en el quinto mes. Es importante remarcar que a $0^{\circ} \mathrm{C}$ no se observó perdida de vacío en ninguna de las muestras.

\begin{tabular}{|c|c|c|c|c|c|}
\hline \multirow{2}{*}{\multicolumn{2}{|c|}{ Parámetros }} & \multicolumn{4}{|c|}{ Picaña $0^{\circ} \mathrm{C}$} \\
\hline & & Mes 2 & Mes 3 & Mes 4 & Mes 5 \\
\hline \multicolumn{2}{|c|}{$\mathrm{pH}$} & 5.6 & 5.5 & 5.4 & 5.4 \\
\hline \multicolumn{2}{|c|}{ Kreiss } & Negativo & Negativo & Negativo & Negativo \\
\hline \multicolumn{2}{|c|}{ Porcentaje Drip } & $0.69 \%$ & $1.46 \%$ & $4.36 \%$ & $3.06 \%$ \\
\hline \multicolumn{2}{|c|}{ Primer olor } & Característico & $\begin{array}{c}\text { Levemente } \\
\text { ácido }\end{array}$ & $\begin{array}{c}\text { Levemente } \\
\text { ácido }\end{array}$ & Ácido. \\
\hline \multicolumn{2}{|c|}{ Segundo olor } & Característico & $\begin{array}{l}\text { Levemente } \\
\text { ácido }\end{array}$ & $\begin{array}{c}\text { Levemente } \\
\text { ácido }\end{array}$ & Ácido. \\
\hline \multirow{3}{*}{$\begin{array}{c}\text { Color del } \\
\text { corte }\end{array}$} & Envasado & Rojo violáceo & Rojo violáceo & Pálido & Rojo \\
\hline & $\begin{array}{l}10 \mathrm{~min} \\
\text { abierto }\end{array}$ & Rojo brillante & Rojo brillante & Pálido & Rojo \\
\hline & $\begin{array}{l}30 \mathrm{~min} \\
\text { abierto }\end{array}$ & Rojo brillante & Rojo brillante & Pálido & Rojo \\
\hline \multicolumn{2}{|c|}{ Color de grasa } & Blanco cremoso & Blanco cremoso & Blanco cremoso & $\begin{array}{c}\text { Blanco cremoso, } \\
\text { algo grisácea }\end{array}$ \\
\hline
\end{tabular}


Tabla 2. Parámetros fisicoquímicos y sensoriales de picaña a $4^{\circ} \mathrm{C}$

\begin{tabular}{|c|c|c|c|c|c|}
\hline \multirow{2}{*}{\multicolumn{2}{|c|}{ Parámetros }} & \multicolumn{4}{|c|}{ Picaña $4^{\circ} \mathrm{C}$} \\
\hline & & Mes 1 & Mes 2 & Mes 3 & Mes 4 \\
\hline \multicolumn{2}{|c|}{$\mathrm{pH}$} & 5.3 & 5.5 & 5.2 & 5.0 \\
\hline \multicolumn{2}{|c|}{ Kreiss } & Negativo & Negativo & Negativo & Negativo \\
\hline \multicolumn{2}{|c|}{ Porcentaje Drip } & $1.43 \%$ & $1.58 \%$ & $3.16 \%$ & $3.48 \%$ \\
\hline \multicolumn{2}{|c|}{ Primer olor } & $\begin{array}{l}\text { Levemente } \\
\text { acido }\end{array}$ & $\begin{array}{l}\text { Levemente } \\
\text { acido }\end{array}$ & Muy ácido & Ácido \\
\hline \multicolumn{2}{|c|}{ Segundo olor } & $\begin{array}{l}\text { Levemente } \\
\text { acido }\end{array}$ & $\begin{array}{l}\text { Levemente } \\
\text { acido }\end{array}$ & Ácido & Ácido \\
\hline \multirow{3}{*}{$\begin{array}{l}\text { Color del } \\
\text { corte }\end{array}$} & Envasado & Pálido & Rojo & Rojo & $\begin{array}{c}\text { Extremos muy } \\
\text { oscuros }\end{array}$ \\
\hline & $\begin{array}{l}10 \mathrm{~min} \\
\text { abierto }\end{array}$ & Pálido & Rojo & Rojo brillante & $\begin{array}{c}\text { Rojo excepto en } \\
\text { zonas oscuras }\end{array}$ \\
\hline & $\begin{array}{l}30 \mathrm{~min} \\
\text { abierto }\end{array}$ & Rojo brillante & Rojo brillante & Rojo brillante & Rojo \\
\hline \multicolumn{2}{|c|}{ Color de grasa } & Blanco cremoso & Blanco cremoso & Blanco cremoso & Algo grisáceo \\
\hline
\end{tabular}

Tabla 3. Parámetros fisicoquímicos y sensoriales de bife a $0^{\circ} \mathrm{C}$

\begin{tabular}{|c|c|c|c|c|c|}
\hline \multirow{2}{*}{\multicolumn{2}{|c|}{ Parámetros }} & \multicolumn{4}{|c|}{ Bife $0^{\circ} \mathrm{C}$} \\
\hline & & Mes 2 & Mes 3 & Mes 4 & Mes 5 \\
\hline \multicolumn{2}{|c|}{$\mathrm{pH}$} & 5.6 & 5.5 & 5.4 & $\overline{5.4}$ \\
\hline \multicolumn{2}{|c|}{ Kreiss } & Negativo & Negativo & Negativo & Negativo \\
\hline \multicolumn{2}{|c|}{ Porcentaje Drip } & $0.27 \%$ & $1.11 \%$ & $1.08 \%$ & No se determinó \\
\hline \multicolumn{2}{|c|}{ Primer olor } & $\begin{array}{c}\text { Característico } \\
\text { intenso }\end{array}$ & $\begin{array}{l}\text { Levemente } \\
\text { ácido }\end{array}$ & Levemente ácido & Levemente ácido \\
\hline \multicolumn{2}{|c|}{ Segundo olor } & Característico & Característico & Característico & Levemente ácido \\
\hline \multirow{3}{*}{$\begin{array}{c}\text { Color del } \\
\text { corte }\end{array}$} & Envasado & Oscuro & Rojo & Rojo & Pálido \\
\hline & $\begin{array}{l}10 \mathrm{~min} \\
\text { abierto }\end{array}$ & Rojo brillante & Rojo brillante & Rojo & Pálido \\
\hline & $\begin{array}{l}30 \mathrm{~min} \\
\text { abierto }\end{array}$ & Rojo brillante & Rojo brillante & Rojo & Pálido \\
\hline \multicolumn{2}{|c|}{ Color de grasa } & Blanco cremoso & Blanco cremoso & $\begin{array}{c}\text { Blanco cremoso, } \\
\text { grisáceo hacia el } \\
\text { cuadril. }\end{array}$ & Rosa grisáceo \\
\hline
\end{tabular}


Tabla 4. Parámetros fisicoquímicos y sensoriales de picaña a $4^{\circ} \mathrm{C}$

\begin{tabular}{|c|c|c|c|c|c|}
\hline \multirow{2}{*}{\multicolumn{2}{|c|}{ Parámetros }} & \multicolumn{4}{|c|}{ Bife $4^{\circ} \mathrm{C}$} \\
\hline & & Mes 1 & Mes 2 & Mes 3 & Mes 4 \\
\hline \multicolumn{2}{|c|}{$\mathrm{pH}$} & 5.5 & 5.5 & 5.3 & 5.3 \\
\hline \multicolumn{2}{|c|}{ Kreiss } & Negativo & Negativo & Dudoso & Negativo \\
\hline \multicolumn{2}{|c|}{ Porcentaje Drip } & $0.89 \%$ & $0.69 \%$ & $0.89 \%$ & $1.23 \%$ \\
\hline \multicolumn{2}{|c|}{ Primer olor } & Característico & Levemente ácido & Ácido & $\begin{array}{l}\text { Ácido muy } \\
\text { fuerte, } \\
\text { sulfhídrico }\end{array}$ \\
\hline \multicolumn{2}{|c|}{ Segundo olor } & Característico & Levemente ácido & Levemente ácido & Ácido \\
\hline \multirow{3}{*}{$\begin{array}{c}\text { Color del } \\
\text { corte }\end{array}$} & Envasado & Rojo & Pálido & Rojo & $-\left(^{(*)}\right.$ \\
\hline & $\begin{array}{l}\text { 10min } \\
\text { abierto }\end{array}$ & Rojo brillante & Rojo brillante & Rojo brillante & - \\
\hline & $\begin{array}{l}30 \mathrm{~min} \\
\text { abierto }\end{array}$ & Rojo brillante & Rojo brillante & Rojo brillante & - \\
\hline \multicolumn{2}{|c|}{ Color de grasa } & Blanco cremoso & Blanco cremoso & Blanco cremoso & - \\
\hline
\end{tabular}

(-): No se tomaron en cuenta por el estado general inaceptable de la muestra.

\section{Parámetros fisicoquímicos y sensoriales}

Los resultados fisicoquímicos y sensoriales se muestran en las Tablas 1, 2, 3 y 4 para los diferentes cortes y temperaturas de almacenamiento.

\section{a. Medida de $\mathrm{pH}$ y rancidez}

Los valores de $\mathrm{pH}$ de las muestras almacenadas a $0^{\circ} \mathrm{C}$ no variaron significativamente durante el período estudiado, y se mantuvieron entre valores de 5.4 y 5.6. En cambio para los cortes almacenados a $4^{\circ} \mathrm{C}$ se observó un descenso marcado hasta valores de 5.3 y 5.0 para bife y picaña, respectivamente. El ensayo de Kreiss dio resultados negativos para ambos cortes en las dos condiciones de almacena- miento, indicando la ausencia de rancidez en las muestras.

\section{b. Volumen de exudado o Drip}

Como se muestra en las tablas 1, 2, 3 y 4, el exudado expresado como Porcentaje Drip mostró incrementos hacia los meses finales del ensayo para cualquiera de los cortes y temperaturas, siendo la picaña en cualquiera de los casos el corte que registró porcentajes de exudado mayores al 3\%.

\section{$\underline{\text { c. Olor de la carne }}$}

En el bife a $4^{\circ} \mathrm{C}$ comenzaron a apreciarse olores ácidos a partir del mes tres de almacenado 
que perduraban más de 10 minutos; es decir, que se manifestaban en el segundo olor; mientras que el bife a $0^{\circ} \mathrm{C}$ no mostró alteraciones en su segundo olor hasta el mes cinco. Para la picaña a $4^{\circ} \mathrm{C}$ también se apreciaron olores ácidos a partir del tercer mes en el primer y segundo olor, mientras que a $0^{\circ} \mathrm{C}$ mostró olores fuertemente ácidos recién a partir del quinto mes.

\section{$\underline{\text { d. Color de la carne }}$}

Las muestras de bife a $4^{\circ} \mathrm{C}$ presentaron color rojo/violáceo normal para la carne envasada al vacío, recuperando su brillo habiendo pasado 10 minutos hasta el tercer mes; aunque a este tiempo, la muestra ya no era aceptable tanto por su olor como por el estado del envase. En el cuarto mes, la muestra se consideró con un aspecto inaceptable en su estado general. Para el bife envasado a $0^{\circ} \mathrm{C}$, el color en el envase se percibió más oscuro en comparación con las muestras a $4^{\circ} \mathrm{C}$; aunque también recuperó el brillo a los 10 minutos, y mantuvo el color rojo hasta el cuarto mes a partir del cual tomó un color pálido. Los cortes envasados de picaña a $0^{\circ} \mathrm{C}$ también tuvieron colores oscuros, recuperando el color rojo brillante luego de 10 minutos en los primeros tres meses. Los cortes de picaña a $4^{\circ} \mathrm{C}$ tuvieron la capacidad de recuperar el tono brillante hasta el tercer mes, luego de este tiempo se observaron alteraciones de color oscuras en los extremos del corte.

\section{e. Color de la grasa}

En la picaña a $0^{\circ} \mathrm{C}$ se mantuvo el color blanco cremoso normal de la grasa de cobertura hasta el cuarto mes, comenzando a observarse un tinte grisáceo en el quinto mes; mientras que la almacenada a $4^{\circ} \mathrm{C}$ mantuvo el color blanco cremoso solo hasta el tercer mes. En el bife a $0^{\circ} \mathrm{C}$, la grasa comenzó a tomar un tono grisáceo hacia la parte del cuadril en el cuarto mes, mientras que a $4^{\circ} \mathrm{C}$ se mantuvo el color blanco cremoso solamente hasta el tercer mes, inclusive.

\section{Análisis microbiológicos}

Tabla 5. Recuento de aerobios mesófilos y enterobacterias en bife y picaña envasados al vacío

$$
\text { y conservados a } 0^{\circ}
$$

\begin{tabular}{|c|c|c|c|c|c|c|c|c|}
\hline \multirow{3}{*}{ Mes } & \multicolumn{4}{|c|}{ Bife log (ufc/g) } & \multicolumn{4}{c|}{ Picaña log (ufc/g) } \\
\cline { 2 - 10 } & \multicolumn{2}{|c|}{ AM } & \multicolumn{2}{c|}{ EB } & \multicolumn{3}{c|}{ AM } & \multicolumn{3}{c|}{ EB } \\
\cline { 2 - 9 } & $\mathbf{0}^{\circ} \mathbf{C}$ & $\mathbf{4}^{\circ} \mathbf{C}$ & $\mathbf{0}^{\circ} \mathbf{C}$ & $\mathbf{4}^{\circ} \mathbf{C}$ & $\mathbf{0}^{\circ} \mathbf{C}$ & $\mathbf{4}^{\circ} \mathbf{C}$ & $\mathbf{0}^{\circ} \mathbf{C}$ & $\mathbf{4}^{\circ} \mathbf{C}$ \\
\hline $\mathbf{0}$ & 2.7 & 2.7 & 0.7 & 0.7 & 3.6 & 3.6 & 0.7 & 0.7 \\
\hline $\mathbf{1}$ & - & 5.0 & - & 2.7 & - & 4.1 & - & 2.7 \\
\hline $\mathbf{2}$ & 5.2 & 7.0 & 0.7 & 5.8 & 4.3 & 5.5 & 0.0 & 4.2 \\
\hline $\mathbf{3}$ & 5.4 & 7.5 & 2.3 & 5.1 & 5.1 & 5.5 & 0.7 & 1.0 \\
\hline $\mathbf{4}$ & 6.5 & 7.7 & 2.6 & - & 6.2 & 6.6 & 0.8 & - \\
\hline $\mathbf{5}$ & 6.5 & - & 1.7 & - & 5.7 & - & 2.0 & - \\
\hline
\end{tabular}

AM: Aerobios mesófilos; EB: Enterobacterias; (-): No se analizaron. 
En la tabla 5 se muestran los recuentos para aerobios mesofilos y enterobacterias realizados para ambos cortes conservados a $0^{\circ} \mathrm{C}$ y $4^{\circ} \mathrm{C}$. Al momento de iniciar el estudio, los recuentos de aerobios totales fueron de 2.7 log ufc/g para el bife y de 3.6 log ufc/g para la picaña. Los aerobios mesófilos se incrementaron durante todo el período de almacenamiento a ambas temperaturas de almacenamiento.

En el caso del bife almacenado a $0^{\circ} \mathrm{C}$ se llegó a valores de $6.5 \mathrm{log} \mathrm{ufc} / \mathrm{g}$ al cuarto mes; y este valor se mantuvo por lo menos hasta el quinto mes. Para los bifes conservados a $4^{\circ} \mathrm{C}$, se llegó a recuentos de $7 \log \mathrm{ufc} / \mathrm{g}$ a los dos meses. Los cortes de picaña tuvieron un comportamiento similar, pero con crecimientos menos pronunciados, llegando en los cortes a $0^{\circ} \mathrm{C}$ a un valor de $6.2 \mathrm{log} \mathrm{ufc} / \mathrm{g}$ a los cuatro meses.

Los recuentos iniciales de enterobacterias en ambos cortes fueron de 0.7 log ufc/g; en los cortes almacenados a $4^{\circ} \mathrm{C}$ lograron aumentar hasta 5.8 log ufc/g a los dos meses de almacenamiento, mientras que a $0^{\circ} \mathrm{C}$ el máximo valor fue de $2.8 \mathrm{log}$ ufc/g en cortes con cuatro meses de almacenamiento.

Por otro lado, se realizaron recuentos de bacterias ácido lácticas a los meses tres y cuatro para los cortes almacenados a $4^{\circ} \mathrm{C}$, obteniéndose valores de $6.4 \pm 0.2$ y $7.4 \pm 1.0 \mathrm{log} \mathrm{ufc} / \mathrm{g}$, respectivamente. Para los cortes a $0^{\circ} \mathrm{C}$, los recuentos de bacterias ácido lácticas se realizaron al cuarto y quinto mes, siendo los resultados $6.6 \pm 0.2$ y $7.4 \pm 0.2 \log \mathrm{ufc} / \mathrm{g}$, respectivamente. En los recuentos de bacterias ácido lácticas no hubo diferencia entre los cortes de bife y los de picaña.

También se evaluó el crecimiento de coliformes totales y E. coli a lo largo del período de almacenamiento; en ambos cortes y para ambas temperaturas no se recuperaron colonias viables. Solamente para coliformes totales se obtuvo al cuarto mes un recuento de $2.6 \pm 0.3$ log ufc/g para ambos cortes y temperaturas de almacenamiento.

En cuanto al exudado, los recuentos de las distintas bacterias siguieron el mismo patrón de crecimiento que sobre la superficie de los cortes pero fueron entre 1.5 y $2 \log$ superiores a los de la superficie de la carne para ambos cortes, y entre 2 y 4 log superiores para enterobacterias. 
Muestras re-envasadas al vacío

Tabla 6. Aspectos sensoriales de las muestras re-envasadas al vacío al segundo mes

\begin{tabular}{|c|c|c|c|}
\hline Parámetros & Cortes de Picaña a $0^{\circ} \mathrm{C}$ & Cortes de Picaña a $4^{\circ} \mathrm{C}$ & Cortes de Bife a $4^{\circ} \mathrm{C}$ \\
\hline Primer olor & Lácteo suave & Ácido & Pútrido, ácido y gaseoso. \\
\hline $\begin{array}{l}\text { Segundo } \\
\text { olor }\end{array}$ & Lácteo suave & Ácido & $\begin{array}{c}\text { Fuerte, lácteo. No es } \\
\text { desagradable }\end{array}$ \\
\hline $\begin{array}{l}\text { Aspecto al } \\
\text { corte }\end{array}$ & Bueno. Algo de jugo & Bueno. Algo de jugo & Bueno. Algo de jugo \\
\hline $\begin{array}{c}\text { Color } \\
\text { envasado }\end{array}$ & $\begin{array}{c}\text { Pálido. Recupera rojo a } \\
\text { los } 10 \mathrm{~min} .\end{array}$ & $\begin{array}{c}\text { Pálido. Recupera rojo a } \\
\text { los } 10 \mathrm{~min} .\end{array}$ & $\begin{array}{c}\text { Pálido. Recupera rojo a } \\
\text { los } 10 \mathrm{~min} .\end{array}$ \\
\hline Color grasa & Blanco crema & Blanco crema & Blanco crema \\
\hline
\end{tabular}

En la tabla 6 se describen parámetros sensoriales del promedio de muestras (dos por tratamiento), que fueron re-envasadas correspondiente al segundo mes del primer envasado, y abiertas catorce días después. En este caso, todas las muestras dieron positivas al ensayo de Kreiss, lo que determina rancidez de la grasa. Se observó cómo los dos tipos de cortes almacenados a $4^{\circ} \mathrm{C}$ presentan una mayor alteración en el olor que los cortes almacenados a $0^{\circ} \mathrm{C}$. Todas las muestras re envasadas conservaron el vacío en el envase durante catorce días almacenadas, tanto a $0^{\circ} \mathrm{C}$ como a $4^{\circ} \mathrm{C}$.
En la tabla 7 se describen los parámetros de las muestras correspondientes al cuarto mes del primer envasado de los cortes que fueron re-envasadas y conservadas, como se indica en la misma (dos muestras por tratamiento). Se evaluaron a los 16 días de almacenamiento. En este caso, al comparar los cortes de picaña y de bife a $0^{\circ} \mathrm{C}$, se observó cómo la picaña presenta un estado de mayor alteración, haciendo hincapié en el primer olor muy ácido, el cual se mantuvo aún en el segundo olor. También se observó que el 75\% de los cortes de picaña presentaban defectos mayores con pérdida de vacío en el envase. 
Tabla 7. Aspectos sensoriales de las muestras re-envasadas al vacío al cuarto mes

\begin{tabular}{|c|c|c|c|}
\hline Parámetros & Cortes de Picaña a $0^{\circ} \mathbf{C}$ & Cortes de Picaña a $4^{\circ} \mathbf{C}$ & Cortes de Bife a 0 $^{\circ} \mathbf{C}$ \\
\hline Primer olor & Muy ácido & Láctico intenso & Ácido \\
\hline $\begin{array}{c}\text { Segundo } \\
\text { olor }\end{array}$ & Muy ácido & Láctico intenso & Láctico intenso \\
\hline $\begin{array}{c}\text { Aspecto al } \\
\text { corte }\end{array}$ & Normal & Normal & Muy mal estado \\
\hline envasado & Rojo & Pálido. Recupera rojo a & Rojo \\
\hline Color grasa 10 min. & Blanco crema & Blanco crema & Blanco crema \\
\hline
\end{tabular}

\section{Envasado y vida útil}

La vida útil de la carne enfriada y envasada al vacío puede ser definida como el momento en el cual el producto deja de ser aceptado por los consumidores. La optimización de las condiciones que permiten prolongarla es un tema relevante para la industria frigorífica, para poder alcanzar mercados lejanos con óptima calidad.

Un factor importante a considerar en la determinación de la vida útil comercial de la carne envasada al vacío es el aspecto general del envase. Si bien, un deterioro del mismo no implica necesariamente que la carne no esté apta para ser consumida, un envase deteriorado con pérdida de vacío no es comercialmente aceptable. En este trabajo se observó que la temperatura de almacenamiento influye en el tiempo al cual los signos de deterioro del envase se hacen evidentes.
En los cortes almacenados a $4^{\circ} \mathrm{C}$ se evidenciaron defectos mayores (burbújas en el exudado y pérdida de vacío) a partir del tercer mes; mientras que a $0^{\circ} \mathrm{C}$, el proceso de deterioro fue más lento. A esta temperatura solo se observaron defectos menores, que no descalifican comercialmente al producto a partir del cuarto mes.

El efecto de la temperatura en el aspecto del envase fue observado por otros autores; por ejemplo, el trabajo de Moschonas et al. (2010) mostró tanto en carne de res como de cordero que el tiempo en el cual se comienza a observar la formación de gas en el envase aumenta significativamente cuando la temperatura de almacenamiento disminuye, prolongando la vida útil comercial del producto.

Durante el estudio se evaluó también como indicador de calidad el porcentaje de drip. Se observaron diferencias entre los cortes es- 
tudiados independientemente de la temperatura de almacenamiento. Los valores obtenidos para el bife siempre estuvieron por debajo del 3\%, mientras que para la picaña - en ambas condiciones de almacenamiento - estuvo por encima del 3\%, pero se mantuvo debajo del 5\%. Este valor se considera un defecto menor, el cual - sin llegar a ser crítico - tiene la probabilidad de ocasionar una falla o reducir materialmente la utilidad del corte (INAC 2009).

Otro aspecto que podría ser descalificativo es la presencia de rancidez (INAC 2009), esta no fue detectada a lo largo del estudio en ninguna de las condiciones de almacenamiento.

En la carne envasada al vacío, el primer olor al abrir el envase determina la aceptación o el rechazo por parte de los consumidores. Un primer olor levemente ácido, que se disipa en pocos minutos dejando el olor característico a la carne cruda, es generalmente aceptado (Edwards, 1985); pero un olor ácido persistente en el tiempo conduce al rechazo. En este estudio, el rechazo por olor desagradable se presentó a distintos tiempos según la temperatura de almacenamiento. Los resultados, tanto para bife angosto como picaña, mostraron que un aumento de $0^{\circ} \mathrm{C}$ a $4^{\circ} \mathrm{C}$ acelera la aparición de olores indeseables, reduciendo la vida útil de cuatro a dos meses. Este efecto también fue observado en otros estudios donde se vio que un aumento en la temperatura de dos grados reduce la vida útil del producto (Youssef, 2014; Gill A. and Gill, 2005); posiblemente debido a un crecimiento más rápido de las bacterias responsables del deterioro y producción de olores desagradables.

Sumado al olor, el color de la carne y de la grasa son otros de los atributos que influyen en la decisión de compra, ya que el consumidor asocia el color con el grado de frescura y calidad (Brewer et al., 2002). En los cortes envasados al vacío se activa la producción de deoximioglobina, ya que se retarda la oxidación; y por lo tanto, el corte envasado permanece con un color rojo púrpura que vira hacia el rojo brillante a los 10 minutos de abierto el envase. De acuerdo a esto, una carne que no recupera su color luego de abierto el envase no es aceptada sensorialmente.

En este estudio, en los cortes conservados a $0^{\circ} \mathrm{C}$ se comienza a detectar cambios leves en la coloración de la carne a partir del cuarto mes. Se observó un comportamiento análogo con la grasa en los cortes a $0^{\circ} \mathrm{C}$ almacenados por cuatro meses o más, donde se observaron tonos grisáceos en la grasa de cobertura, pudiendo ser éste un factor de rechazo, ya que el ideal es un color blanco-cremoso. En los cortes almacenados a $4^{\circ} \mathrm{C}$ no se observaron cambios significativos de color durante los dos primeros meses de almacenamiento.

Tanto la presencia de gas en el envase como la aparición de olores desagradables pueden 
explicarse, en parte, por un aumento en el número de los microorganismos que estaban presentes en la carne al momento de envasar. Las carnes utilizadas al momento de envasarse tenían valores de recuentos de microorganismos dentro de los valores aceptados: $5 \times 10^{5}$ ufc/g para aerobios mesófilos, 50 ufc/g para E. coli y $1 \times 10^{3} \mathrm{ufc} / \mathrm{g}$ para enterobacterias (EFSA 2005, DGSG 2011).

Estos valores se fijan como indicadores de higiene y calidad en la carne al momento de envasarse, no habiendo límites fijados como determinantes de vida útil. En este respecto, la evolución microbiológica indicó que durante el período de almacenamiento tanto a $0^{\circ} \mathrm{C}$ como a $4^{\circ} \mathrm{C}$ existió crecimiento de microorganismos aerobios mesófilos totales, enterobacterias y de bacterias ácido lácticas, siendo mayores los recuentos de aerobios en las muestras conservadas a $4^{\circ} \mathrm{C}$, alcanzando valores cercanos a $106 \mathrm{ufc/g}$, a partir de los dos meses de envasado en ambos cortes. En los cortes conservados a $0^{\circ} \mathrm{C}$, estos valores de recuentos críticos se observaron recién a partir de los cuatro meses, coincidiendo con el momento al que se percibieron los olores ácidos persistentes.

El tipo de bacteria que se puede desarrollar en estas condiciones de temperatura y anaerobiosis va a depender del $\mathrm{pH}$ inicial de la carne al momento de envasar. Las condiciones de maduración en cámara (36 horas a temperaturas entre $4^{\circ} \mathrm{C}$ y $10^{\circ} \mathrm{C}$ ) exigidas a Uruguay por los mercados internacionales, aseguran que el $\mathrm{pH}$ de la carne esté por debajo de 5.6 al momento de envasar (USDA 2002). A este $\mathrm{pH}$, la flora de descomposición estará dominada por bacterias acido lácticas de los géneros Lactobacillus, Leuconostoc, y Carnobacterium (Gill and Greer, 1993; Gill and Gill, 2005).

No hay valores máximos establecidos para bacterias acido lácticas en carnes de res envasadas a vacío, pero valores de ente 6 y 7 $\log \mathrm{ufc} / \mathrm{g}$ se asocia con la presencia de olores desagradables (Gill and Greer, 1993).

Los recuentos para bacterias acido lácticas fueron mayores para los cortes almacenados a $4^{\circ} \mathrm{C}(7.4 \pm 1.0 \mathrm{log}$ ufc/g $)$ que para los cortes a $0^{\circ} \mathrm{C}(6.6 \pm 0.2 \log \mathrm{ufc} / \mathrm{g})$. Esta diferencia en número podría en parte explicar la aparición de olores ácidos persistentes y la diferencia que se observa en los valores de $\mathrm{pH}$, a partir del cuarto mes entre los cortes a $0^{\circ} \mathrm{C}$ y a $4^{\circ} \mathrm{C}$, ya que entre los principales metabolitos de estas bacterias figura el acido láctico que puede producir un descenso de 0.2 y 0.5 unidades de $\mathrm{pH}$.

Por otro lado, en los cortes de bife a $4^{\circ} \mathrm{C}$ - luego de los dos meses - hubo un aumento de enterobacterias (5.8 log ufc/g) que podría ser la causa de la aparición de olores pútridos (Gill and Gill, 2009; Edwards, 1985), y de la producción de gases (Brightwell et al, 2007). 
Sumado a todo lo anterior, debemos considerar el hecho que los mercados de destino de las exportaciones de Uruguay generalmente fraccionan los cortes primarios en porciones unitarias y los re-envasan para su venta minorista. Por lo tanto, la carne debe llegar a destino con una vida útil que permita un adecuado manejo comercial por los mercados compradores.

El re-envasado de los cortes, cuya finalidad fue simular este proceso, sugiere que no es conveniente realizar esta manipulación con cortes primarios que tengan cuatro meses de envasado, independientemente de la temperatura a la que estuvieron almacenados, ya que el producto re-envasado tendría una vida útil menor a 15 días, debido a la aparición de olores ácidos, rancidez y pérdida de vacío en el envase. Al realizar la misma simulación, a partir de cortes primarios conservados a $0^{\circ} \mathrm{C}$ con dos meses de envasado, los mismos conservaron los parámetros de calidad al cabo de 15 días. Observaciones similares fueron reportadas en carnes australianas por Rodas (2011) y Grau (1981).

\section{Conclusiones}

En suma, los cortes de carne obtenidos en las condiciones de producción que se manejan en Uruguay, envasados al vacío y almacenados a $0^{\circ} \mathrm{C}$, mantienen las características sensoriales y fisicoquímicas en condiciones adecuadas para su comercialización hasta los cuatro meses. Dicho tiempo supera al tiempo sugerido de 90 días para el comercio internacional (Bell, R.G. and Garout A.M., 1994), lo que permite un buen manejo comercial del producto, siempre y cuando estén bajo un control de temperatura estricto. En el caso que los cortes sean re-envasados para su comercialización se recomienda usar cortes primarios que no tengan más de dos meses de almacenamiento.

Por otro lado, los cortes envasados al vacío almacenados a $4^{\circ} \mathrm{C}$ mantienen sus características durante dos meses, pero ya en el tercer mes presentan cambios organolépticos y fisicoquímicos que los hacen comercialmente inaceptables.

Esta sustancial diferencia entre ambas temperaturas de almacenamiento se deberá tener especialmente en cuenta no solo para la comercialización en el mercado internacional, sino para el manejo del producto en el mercado interno donde el control de temperatura en los locales comerciales no es tan estricto.

Se sugiere entonces que la máxima vida útil para los cortes de picaña y bife angosto, envasados al vacío, sea de cuatro meses si se conservan $0^{\circ} \mathrm{C}$. Un aumento de la temperatura de almacenamiento reduce significativamente la vida útil del producto. 


\section{Referencias}

Bell, R. G. y Garout, A. M. (1994). The effective product life of vacuum-packaged beef imported into Saudi Arabia by sea, as assessed by chemical, microbiological and organoleptic criteria. Meat Science 36:381-396.

Brewer, M. S.; Jensen, J.; Prestat, C.; Zhu, L. G.; Mckeith, F. K. (2002). Visual acceptability and consumer purchase intent of pumped pork loin roasts. J. Muscle Foods 13:53-68.

Brightwell, G.; Clemens, R.; Urlich, Sh.; Boerema, J. (2007). Possible involvement of psychrotolerant Enterobacteriaceae in blown pack spoilage of vacuum-packaged raw meats. International Journal of Food Microbiology 119:334-339.

Bruhn, J. B.; Christensen, A. B.; Flodgaard, L. R.; Nielsen, K. F.; Larsen, T. O. and Givskov, M. (2004). Presence of acylated homoserine lactones (AHLs) and AHL-producing bacteria in meat and potential role of AHL in spoilage of meat. Appl Environ Microb 70:4293-302.

Edwards, R. A.; Dainty, R. H.; y Hibbard, C. M. (1985). Putrescine and cadaverine formation in vacuum packed beef. J. Appl Bacteriol 58:13-19.

Gianfelici, T.; Roncoroni, S.; Guadalupe, O. (1982). Manual de laboratorio de la industria cárnica. Centro de investigación y tecnología de carnes del sistema INTI.

Gill C.O.; Phillips, D.M. y Harrison, J.C.L. (1988). Product temperature criteria for shipment of chilled meats to distant markets, in Refrigeration for Food and People. International Institute of Refrigeration, Paris, pp. 40-47.

Gill, C. O. y Harrison, J. C. L. (1989). The storage life of chilled pork packages under carbon dioxide. Meat Science 26:313-24.

Gill, C. O. y Greer, G. G. (1993). Enumeration and identification of meat spoilage bacteria. Technical bulletin 1993-8E. Lacombe, Alberta, Canada: Agriculture Canada, p. 1-24.

Gill C.O.; Jones, T.; Rahn, K.; Campbell, S.; LeBlanc, D.I.; Holley, R.A.; et al. (2002) Temperatures and ages of boxed beef packed and distributed in Canada. Meat Science 60:401-410.

Gill, A. O.; Gill, C. O. (2005). Preservative packaging for fresh meats, poultry and fin fish. In: Han, J. H. editor. Innovations in food packaging. New York, Elsevier Academic. P 204-26. 
Gill, A. y Gill, C.O. (2009). Packaging and the shelf life of fresh red and poultry meats, in Food Packaging and Shelf Life, ed. by Robertson GL. CRC Press, Boca Raton, FL, pp 259-277.

Gram, L., Ravn, L., Rasch, M., Bruhn, J.B., Christensen, A.B., Givskov, M., (2002). Food spoilage - interactions between food spoilage bacteria. International Journal of Food Microbio$\log$ 78, 79-97.

Lucquin, I; Zagorec, M; Champomier-Vergés; Chaillou, S, (2011). Article in press. Fingerprint of lactic acid bacteria population in beef carpaccio is influenced by storage processs and seasonal changes. Food Microbiology, 1-10.

Lucquin, I.; Zagorec, M.; Champomier-Vergès, M.; Chaillou, S. (2012). Fingerprint of lactic acid bacteria population in beef carpaccio is influenced by storage process and seasonal changes. Food Microbiology. 29, 187-196.

Moschonas, G.; Bolton, D.J.; Sheridan, J.J.; McDowell, D.A. (2010). The effect of storage temperature and inoculum level on the time of onset of 'blown pack' spoilage. Journal of Applied Microbiology. 108:532-539.

Nychas, G; Panos, Skanadamis, P; Tassou, C; Koutsoumanis, K; (2008). Meat spoilage during distribution. Meat Science, 78, 77-89.

Rodas-González, A. et al (2011). Evaluation of the storage life of vacuum packaged Australian beef. Meat Science, 88, 128-138.

Spooncer, W.F; (1988). Vaccum packed meat. Meat quality, packaging new products workshop. Townsville, Mackay, Rockhampton, Australia.

Unión Europea, Europan Food Safety Authority (2005). Reglamento (CE) nº 2073/2005 de la Comisión de 15 de noviembre de 2005 relativo a criterios microbiológicos aplicables a productos alimenticios.

Uruguay, Instituto Nacional de Carnes (2004). Manual de Carnes Bovina y Ovina. Handbook of Uruguayan Meat.

Uruguay, Instituto Nacional de Carnes (2009). Manual de Control de Calidad http://www.inac. gub.uy/innovaportal/file/4752/1/manual_cocc_301009_completo.pdf. 
Uruguay, Ministerio de Ganadería Agricultura y Pesca (2011). Dirección General de Servicios Ganaderos. DGSG/No 42/2011.

Uruguay, United States Deparment of Agriculture (2002). Animal and Plant Health Inspection Service. Risk assessment- Importation of fresh (chilled or frozen) beef from Uruguay.

Vold, L; Holck, A; Wasteson, Y; Nissen, H; (2000). High levels of background flora inhibits growth of Escherichia coli O157:H7 in ground beef. Int J Food Microbiology 56, 219-225.

Youssef, M.K.; Gill, A; and Gill, C. O. (2009). Packaging and the shelf life of fresh red and poultry meats, in food packaging and shelf life. Ed. by Robertson GL. CRC, Press, Boca Raton, FL pp 259-277.

Youssef, MK; Gill, CO; Yang, X. (2014). Storage life at $2{ }^{\circ} \mathrm{C}$ or $-1.5^{\circ} \mathrm{C}$ of vacuum packaged boneless and bone-in cuts from decontaminated beef carcasses. J. Sci. Food Agric. 94(15): 3118-24. 